\title{
Onset of blood lactate accumulation as a predictor of performance in top athletes Comienzo de la acumulación de lactato sanguíneo como predictor del rendimiento en atletas de élite
}

\author{
Jordan Santos-Concejero, Cristina Granados, Iraia Bidaurrazaga-Letona, Jon Zabala-Lili, Jon Irazusta, Susana María Gil \\ Universidad del País Vasco
}

Resumen: El objetivo principal de este estudio fue investigar si el comienzo de la acumulación de lactato en sangre $\left(\mathrm{V}_{\mathrm{OBLA}}\right)$ es un buen predictor del rendimiento de mediofondo y fondo en atletas entrenados. Veintidós corredores tomaron parte en este estudio. Todos completaron un test máximo incremental en tapiz rodante para determinar los parámetros fisiológicos máximos así como la $\mathrm{V}_{\text {OBLA }}$. Se analizaron las relaciones entre la $\mathrm{V}_{\text {OBLA }}$ y el ritmo de carrera de $10 \mathrm{~km}\left(\mathrm{~V}_{10 \mathrm{~K}}\right)$ y $3 \mathrm{~km}\left(\mathrm{~V}_{3 \mathrm{~K}}\right)$. La $\mathrm{V}_{\text {OBLA }}$ fue de $17.7 \pm 1.2 \mathrm{~km} \cdot \mathrm{h}^{-1}$ y las $\mathrm{V}_{10 \mathrm{~K}} \mathrm{y} \mathrm{V}_{3 \mathrm{~K}}$ fueron $21.1 \pm 0.7 \mathrm{~km} \cdot \mathrm{h}^{-1} \mathrm{y} 19.0 \pm 0.8 \mathrm{~km} \cdot \mathrm{h}^{-1}$, respectivamente. Se encontró una correlación lineal significativa entre la $\mathrm{V}_{\mathrm{OBLA}} \mathrm{y} \mathrm{V}_{10 \mathrm{~K}}(r=0.761, P<0.05)$ y entre $\mathrm{V}_{\text {OBLA }} \mathrm{y} \mathrm{V}_{3 \mathrm{~K}}(r=0.561, P<0.05)$. Estos resultados indican que la $\mathrm{V}_{\mathrm{OBLA}}$ está altamente asociada al rendimiento de la carrera de acuerdo a $\mathrm{V}_{10 \mathrm{~K}} \mathrm{yV}_{3 \mathrm{~K}}$ en atletas entrenados. Palabra clave: Resistencia, OBLA, correlación, carrera a pie.

Abstract: The main purpose of this study was to investigate whether the onset of blood lactate accumulation velocity ( $\mathrm{V}_{\text {OBLA }}$ ) is a good predictor of middle- and long-distance running performance in well-trained endurance runners. Twenty-two well-trained runners participated in this study. All participants completed a incremental test on a treadmill to determine maximal physiological variables the $\mathrm{V}_{\text {OBLA }}\left(4 \mathrm{mmol} \cdot \mathrm{L}^{-1}\right.$ of lactate concentration). The relationships between $\mathrm{V}_{\mathrm{OBLA}}$ and the best $\left.10-\mathrm{km}_{(10 \mathrm{~K}}\right)$ and $3-\mathrm{km}\left(\mathrm{V}_{3 \mathrm{~K}}\right)$ race pace were analyzed. The velocity for $\mathrm{V}_{\mathrm{OBLA}}$ was $17.7 \pm 1.2 \mathrm{~km} \cdot \mathrm{h}^{-1}$ and the velocities for $\mathrm{V}_{10 \mathrm{~K}}$ and $\mathrm{V}_{3 \mathrm{~K}}$ were $21.1 \pm 0.7 \mathrm{~km} \cdot \mathrm{h}^{-1}$ and $19.0 \pm 0.8 \mathrm{~km} \cdot \mathrm{h}^{-1}$, respectively. A positive linear relationship was found between $\mathrm{V}_{\mathrm{OBLA}}$ and $\mathrm{V}_{10 \mathrm{~K}}(r=0.761, P<0.05)$ and between $\mathrm{V}_{\mathrm{OBLA}}$ and $\mathrm{V}_{3 \mathrm{~K}}(r=0.561, P<0.05)$. These results indicate that $\mathrm{V}_{\mathrm{OBLA}}$ is highly associated to running performance according to $\mathrm{V}_{10 \mathrm{~K}}$ and $\mathrm{V}_{3 \mathrm{~K}}$ in well-trained runners..

Key words: Endurance, OBLA, correlation, running.

\section{Introduction}

Several researchers have demonstrated that, in the endurance performance, the ability to run without accumulating lactate is more important than the maximum oxygen uptake $\left(V \mathrm{O}_{2 \max }\right)$ or the energy cost of running (Cr) (Yoshida, Udo, Iwai \& Yamaguchi, 1993; Grant, Craig, Wilson, \& Aitchison, 1997). This concept of anaerobic threshold was firstly proposed in order to express the loss of linear relationship between ventilation and the oxygen uptake $\left(\mathrm{VO}_{2}\right)$, which coincides with lactate accumulation (Wasserman \& Mcllroy, 1964). Later, it was redefined as the work rate or $V \mathrm{O}_{2}$ just below the point where lactate begins to systematically increase from its resting level exercise value during an incremental exercise test (Wasserman, Whipp \& Davis, 1981). Since then, different blood lactate indices have been proposed to measure the ability to run without accumulating lactate, such as lactate threshold (LT), maximal lactate steady state (MLSS), or the onset of blood lactate accumulation (OBLA).

OBLA is the exercise intensity corresponding to $4 \mathrm{mmol} \cdot \mathrm{L}^{-1}$ lactate concentration, which represents the maximal workload of steady-state lactate concentration (Figueira, Caputo, Pelarigo, \& Denadai, 2008) and which corresponds to the transition from a tolerable workload to a more severe intensity (Chmura \& Nazar, 2010). Different studies have shown the importance of OBLA in the long distance running performance and it has also been suggested as a sensitive indicator of the training induced adaptations and a sensitive discriminator between elite and good athletes (Tanaka, 1990).

It should be noted that many of these studies where performed with only a small number of participants (Abe, et al., 1999), non-trained subjects (Tanaka, Matsuura, Kumagai, Matsuzaka, Hirakoba \& Asan, 1983) or in non-elite athletes (Sjodin \& Jacobs, 1981; Grant, et al., 1997). Therefore, the main purpose of this study was to investigate if the onset of blood lactate accumulation velocity $\left(\mathrm{V}_{\text {OBLA }}\right)$ could be a good predictor of running performance in well-trained endurance athletes.

Fecha recepción: 01-07-12 - Fecha envío revisores: 01-07-12 - Fecha de aceptación: 30-07-12 Correspondencia: Jordan Santos Concejero

Portal de Lasarte 71

01007, Vitoria-Gasteiz, Álava (Spain)

E-mail: jordan.santos@ehu.es

\section{Methods}

\subsection{Subjects}

Twenty-two well-trained runners ( $28.6 \pm 6.4$ years) participated in the study. Before participation, subjects were medically examined to ensure that they had no signs of cardiovascular, musculoskeletal and metabolic diseases. The Ethics Committee for research on Human subjects at the University of Basque Country (CEISH/GIEB) approved this study. All athletes were informed about all the tests and the possible risks involved and signed a written informed consent prior to testing.

All subjects had participated in international or national level competitions. The best record in 3000 meters and 10000 meters of each subject was recorded and the pace was calculated $\left(\mathrm{V}_{3 \mathrm{~K}}\right.$ and $\mathrm{V}_{10 \mathrm{~K}}$. respectively). Athletes were encouraged to be well rested and to abstain from hard training sessions and competitions the days before testing.

\subsection{Procedures}

Anthropometry. Height (cm) and body mass $(\mathrm{kg})$ were measured with the use of a precision stadiometer and a balance (Seca, Bonn, Germany), and body mass index (BMI) was calculated. Eight skinfold sites (biceps, triceps, subscapular, supraspinale, abdominal, suprailiac, mid-thigh, and medial calf) were measured in duplicate with a skinfold caliper (Holtain, Crymych, UK) by the same researcher and the sum of skinfolds was determined. The body fat percentage was calculated for each athlete, as described elsewhere (Yuhasz, 1974).

Peak treadmill lactate test. All subjects completed a maximal incremental running test at a $1 \%$ gradient on a treadmill (ERGelek EG2, Vitoria-Gasteiz, Spain). The test started at $9 \mathrm{~km} \cdot \mathrm{h}^{-1}$ without previous warm up. Velocity was increased by $1.5 \mathrm{~km} \cdot \mathrm{h}^{-1}$ every 4 minutes until volitional exhaustion, with a minute recovery between each stage. The treadmill was calibrated using a measuring wheel (ERGelek, VitoriaGasteiz, Spain) with a measurement error $<0.5 \mathrm{~m}$ per $100 \mathrm{~m}$ interval. Testing sessions were performed under similar environmental conditions $\left(20-24^{\circ} \mathrm{C}, 45-55 \%\right.$ relative humidity).

During the test gas exchange ratio (RER) were continuously measured using a calibrated gas analyzer system (Ergocard, Medisoft, Sorinnes, Belgium). The gas analyzer was calibrated prior to each session according to the manufacturer's instruction. Volume calibration was performed at different flow rates with a $3 \mathrm{~L}$ calibration syringe (Medisoft, 
Sorinnes, Belgium) allowing an error $\mathrm{d} \gg 2 \%$, and gas calibration was performed automatically by the system using both ambient and precision reference gases $\left(\mathrm{CO}_{2} 4.10 \% ; \mathrm{O}_{2} 15.92 \%\right.$ ) (Linde Gas, Germany). $V \mathrm{O}_{2}$ was also normalized per $\mathrm{kg}^{0.75}$ to reduce the influence of body mass (Helgerud et al, 2010). Heart rate (HR) was recorded by a heart rate monitor (Polar RS800, Kempele, Finland).

Immediately after each exercise stage, capillary blood samples from the earlobe were obtained and lactate concentration was determined with the use of a portable lactate analyzer (Lactate Pro, Arkray, KDK Corporation, Kyoto, Japan.). This system has been validated previously (Tanner, Fuller \& Ross, 2010).

Athletes were considered to have attained their maximal ability when three of the following criteria were fulfilled: 1) a plateau in $V \mathrm{O}_{2}$; 2) RER $>1.15$; 3) HR within 5 beats $\mathrm{min}^{-1}$ of theoretical maximal HR (220-age); 4) lactate concentration $\left.>8 \mathrm{mmol} \cdot \mathrm{L}^{-1} ; 5\right) \mathrm{RPE}=10$.

Determination of $V_{O B L A^{*}} \cdot \mathrm{V}_{\text {OBLA }}$ was calculated by interpolation, expressing the collected blood lactate data of each subject in the peak treadmill lactate test as a function of running velocity. A quadratic equation was used to perform the regression of the lactate concentration and velocity

\subsection{Statistics}

Statistical analyses of data were performed using the Statistical Package for the Social Sciences 15.0 software package (StatSoft, USA). Results are all presented as means, standard deviation (SD) and coefficient of variance $\left(\mathrm{CV} ; \mathrm{SD} \cdot\right.$ mean $\left.^{-1} \cdot 100\right)$. The relationships between $\mathrm{V}_{\mathrm{OBLA}}$ and the average velocities of the individual's running performance were evaluated using a linear regression analysis.

Significance for all analyses was set at $P<0.05$.

\section{Results}

Table 1 shows the results of the anthropometrical parameters and running performance data. The $\mathrm{CV}$ was lower than $10 \%$ in the height, mass and BMI, despite the big variations in factors related to body fat. A small CV of the athlete's performance was observed according to

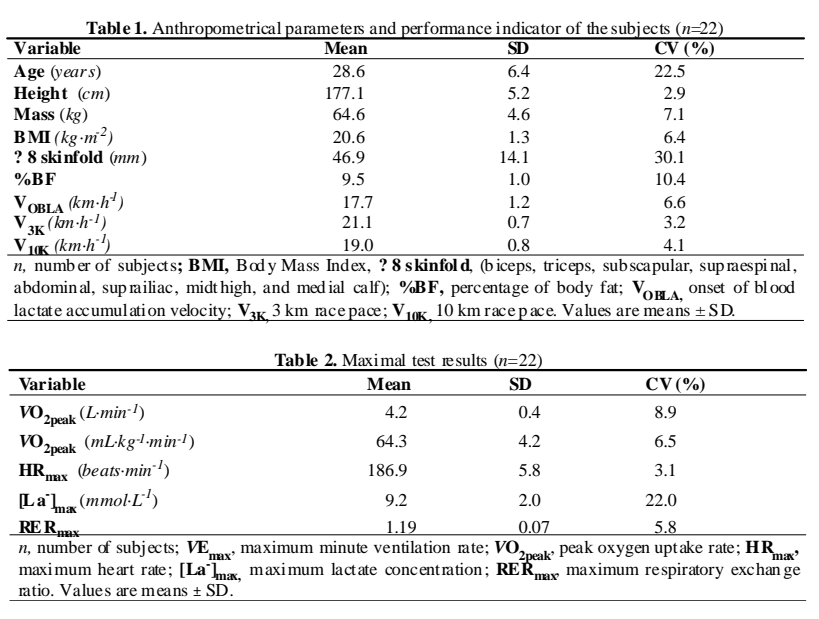

their $\mathrm{V}_{3 \mathrm{~K}}$ and $\mathrm{V}_{10 \mathrm{~K}}$ results $(<7 \%)$, which indicates that all athletes were of similar athletic level.

Maximal test results are listed in table 2. All physiological values, apart from the maximal lactate concentration $\left(\left[\mathrm{La}^{-}\right]_{\max }\right)$, did not exceed the $10 \%$ in the $\mathrm{CV}$, which means that the subjects were a homogeneous group.

Figure 1 shows the relationship of $\mathrm{V}_{\mathrm{OBLA}}$ and running performance $\left(\mathrm{V}_{3 \mathrm{~K}}\right.$ and $\left.\mathrm{V}_{10 \mathrm{~K}}\right) . \mathrm{V}_{\text {OBLA }}$ was closely correlated with $\mathrm{V}_{3 \mathrm{~K}}$ and $\mathrm{V}_{10 \mathrm{~K}}(r=0.561$, $P<0.05$ and $r=0.762, P<0.01$, respectively) despite the small variation among subject's running performance.

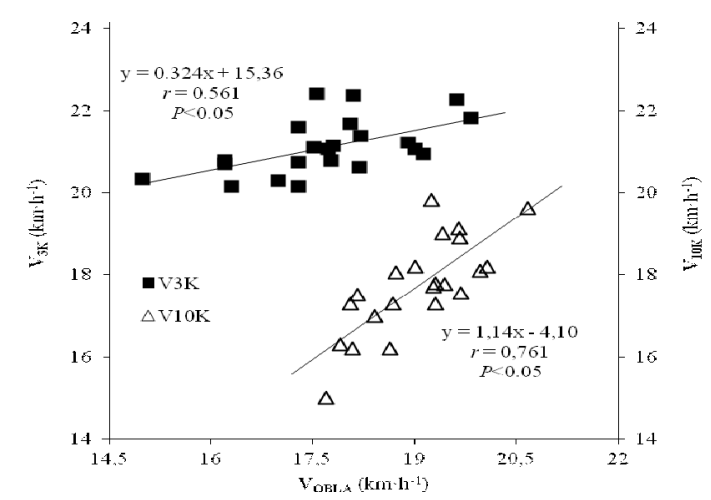

Figure 1. The rel ati onship between running velocity corresponding to the onset of blood lact ate accumulat ion $\left(\mathrm{V}_{\mathrm{OBLA}}\right)$ and the running performance according to the $3 \mathrm{~km}$ race vel ocity $\left(\mathrm{V}_{3 \mathrm{~K}}\right)$ and $10 \mathrm{~km}$

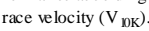

\section{Discussion}

The major finding in this study was the observed significant relationship between $\mathrm{V}_{\mathrm{OBLA}}$ and the middle and long distance running performance according to the 3000 and 10000 meters race velocity. These results are in agreement with previous studies, which have shown the validity of $\mathrm{V}_{\mathrm{OBLA}}$ as a predictor of aerobic performance (Billat, 1996), especially in marathon (Sjodin \& Jacobs, 1981) and in those running events of $16 \mathrm{~km}$ or shorter distances (Tanaka, 1990). In contrast, Abe et al. (1999) did not find a relationship between $\mathrm{V}_{\text {OBLA }}$ and 10-km performance and suggested the use of HR obtained at OBLA instead of $\mathrm{V}_{\text {овцА }}$ itself. Indeed, their findings may have possibly been influenced by out of laboratory testing conditions and/or a small sample size.

Several studies have demonstrated that $\mathrm{V}_{\text {OBLA }}$ is significantly related to middle distance running performance in elite female athletes (Yoshida, et al., 1993) and non-elite male athletes (Grant, et al., 1997). However, the current study is the first finding a significant relationship between $\mathrm{V}_{\mathrm{OBLA}}$ and middle distance performance according to the 3000 meters race pace in well-trained male athletes. Although significance was found between these variables, the correlation coefficients in our study only explain a small percentage of the 3 - and $10-\mathrm{km}$ performances of the well-trained male athletes. Thus, the evidence from our study investigating well-trained endurance male athletes cannot be fully suggested as a predictor for middle- and long-distance running performances.

It is also known that exercise intensity associated to a fixed blood lactate concentration can vary widely as a result of nutrition, prior stress, site of blood acquisition as well as the method of blood sampling (Robergs, Chwalbinska-Moneta, Mitchell, Pascoe, Houmard \& Costill, 1990; Coyle, 1995; Roecker, Schotte, Niess, Horstmann \& Dickhuth, 1998; Feliu, et al., 1999). Researchers have also proposed that $4 \mathrm{mmol} \cdot \mathrm{L}^{-}$ ${ }^{1}$ blood lactate does not take into account inter-individual variability of the LT, thus may not be objective (Stegmann \& Kindermann, 1982). These considerations together with the above-mentioned findings imply that the fixed $4 \mathrm{mmol} \cdot \mathrm{L}^{-1}$ blood lactate may not represent the same exercise intensity in runners of varying athletic ability.

Despite the significant correlations found between $\mathrm{V}_{\mathrm{OBLA}}$ and performance times in this study and previous studies (Sjödin \& Jacobs, 1981; Tanaka \& Matsuura, 1984; Föhrenbach, Mader \& Hollmann, 1987), several researchers have argued against $\mathrm{V}_{\text {OBLA }}$. It has been found that lactate values measured in the blood are not necessarily indicative of the levels of lactate produced in active muscles (Gladden, 2004). It is also proposed that well-trained runners are likely to have an enhanced lactate clearance capacity (Donovan \& Pagliassotti, 1989). Therefore, the use of $\mathrm{V}_{\text {ОВLA }}$ should be strictly standardized, if not should be used cautiously when programming training sessions, evaluating aerobic capacity or predicting running performance.

In summary, a high relationship between $\mathrm{V}_{\mathrm{OBLA}}$ and $\mathrm{V}_{3 \mathrm{~K}}$ and $\mathrm{V}_{10 \mathrm{~K}}$ was observed in current study, which may indicate that this parameter 
is an appropriate index to predict the running performance. However, despite a significant relationship between $\mathrm{V}_{\text {OBLA }}$ and both $\mathrm{V}_{3 \mathrm{~km}}$ and $\mathrm{V}_{10 \mathrm{~km}}$, the obtained correlation coefficients only accounted for a small part of the variance in the performance of well-trained athletes in our study. Therefore, we conclude that $\mathrm{V}_{\text {OBLA }}$ is associated with both middleand long-distance race performances but caution should be taken when relying on this measure to determine performance times.

\section{Conclusions}

$\mathrm{V}_{\text {OBLA }}$ is associated with both middle- and long-distance race performances and therefore could be considered as an adequate measure for training status and performance monitoring in athletes of similar athletic ability and different distance specialization.

Although, $\mathrm{V}_{\text {OBLA }}$ should be used cautiously because it does not take into account inter-individual variability in the lactate threshold and it only can explain a small percentage of the running performance.

\section{References}

Abe, D., Sakaguchi, Y., Tsuchimochi, H., Endo, M., Miyake, K., Miyahiro, S.... Niihata, S. (1999). Assessment of longdistance running performance in elite male runners using onset of blood lactate accumulation. Applied Human Science: Journal of Physiological Anthropology, 18, 25-29.

Billat, L. V.(1996). Use of blood lactate measurements for prediction of exercise performance and for control of training. Recommendations for long-distance running. Sports Medicine, 22, 157-175.

Chmura, J., \& Nazar, K. (2010). Parallel changes in the onset of blood lactate accumulation (OBLA) and threshold of psychomotor performance deterioration during incremental exercise after training in athletes. International Journal of Psychophysiology: Official Journal of the International Organization of the Psycophysiological Society, 75, 287-290.

Coyle, E.F. (1995). Integration of the physiological factors determining endurance performance ability. Exercise and Sport Sciences Reviews, 23, 25-63.

Donovan, C.M. \& Pagliassotti, M.J. (1999). Endurance training enhances lactate clearance during hyperlactatemia. American Journal of Physiology, 257,E782-789.

Feliu, J., Ventura, J.L., Segura, R., Rodas, G, Riera, J., Estruch, A. ... \& Capdevila, L. (1999). Differences between lactate concentration of samples from ear lobe and the finger tip. Journal of Physiology and Biochemistry, 55, 333-339.

Figueira, T. R., Caputo, F., Pelarigo, J. G., \& Denadai, B. S. (2008). Influence of exercise mode and maximal lactate-steady-state concentration on the validity of OBLA to predict maximal lactate-steady-state in active individuals. Journal of Science and Medicine in Sport / Sports Medicine Australia, 11, 280-286.

Föhrenbach, R., Mader, A. \& Hollmann, W. (1987). Determination of endurance capacity and prediction of exercise intensities for training and competition in marathon runners. International Journal of Sports Medicine, 8, 11-18.

Gladden, L.B. (2004). Lactate metabolism: a new paradigm for the third millennium. Journal of Physiology, 558, 5-30.

Grant, S., Craig, I., Wilson, J., \& Aitchison, T. (1997). The relationship between $3 \mathrm{~km}$ running performance and selected physiological variables. Journal of Sports Science, 15, 403-410.

Robergs, R.A., Chwalbinska-Moneta, J., Mitchell, J.B., Pascoe, D.D., Houmard, J. \& Costill, D.L. (1990). Blood lactate threshold differences between arterialized and venous blood. International Journal of Sports Medicine, 11, 446-451.

Roecker, K., Schotte, O., Niess, A.M., Horstmann, T. \& Dickhuth, H.H. (1998).Predicting competition performance in long-distancerunning by means of a treadmill test. Medicine \& Science in Sports \& Exercise, 30, 1552-1557.

Sjödin, B., \& Jacobs, I. (1981). Onset of blood lactate accumulation and marathon running performance. International Journal of Sports Medicine, 2, 23-26.

Stegmann, H. \& Kindermann, W.(1982). Comparison of prolonged exercise tests at the individual anaerobic threshold and the fixed anaerobic threshold of $4 \mathrm{mmol} . \mathrm{L}^{-1}$ lactate. International Journal of Sports Medicine, 3, 105-110.

Tanaka, K. (1990). Lactate-related factors as a critical determinant of endurance. The Annals of Physiological Anthropolology, 9, 191-202.

Tanaka, K., Matsuura, Y., Kumagai, S., Matsuzaka, A., Hirakoba, K., \& Asano, K. (1983). Relationships of anaerobic threshold and onset of blood lactate accumulation with endurance performance. European Journal of Applied Physiology and Occuppational Physiology, 52, 5156.

Tanner, R. K., Fuller, K. L., \& Ross, M. L. (2010). Evaluation of three portable blood lactate analysers: Lactate Pro, Lactate Scout and Lactate Plus. European Journal of Applied Physiology, 109, 551559.

1 Wasserman, K., \& Mcllroy, M. B. (1964). Detecting the threshold of anaerobic metabolism in cardiac patients during exercise.http:// www.ncbi.nlm.nih.gov/pubmed/14232808 The American Journal of Cardiology, 14, 844-852.

Wasserman, K., Whipp, B. J., \& Davis, J. A. (1981). Respiratory physiology of exercise: metabolism, gas exchange, and ventilatory control. International Review of Physiology, 23, 149-211.

Yoshida, T., Udo, M., Iwai, K., \& Yamaguchi, T. (1993). Physiological characteristics related to endurance running performance in female distance runners. Journal of Sports Science, 11, 57-62.

Yuhasz, M. S. (1974). Physical fitness Manual, London, Ontario: University of Western Ontario.
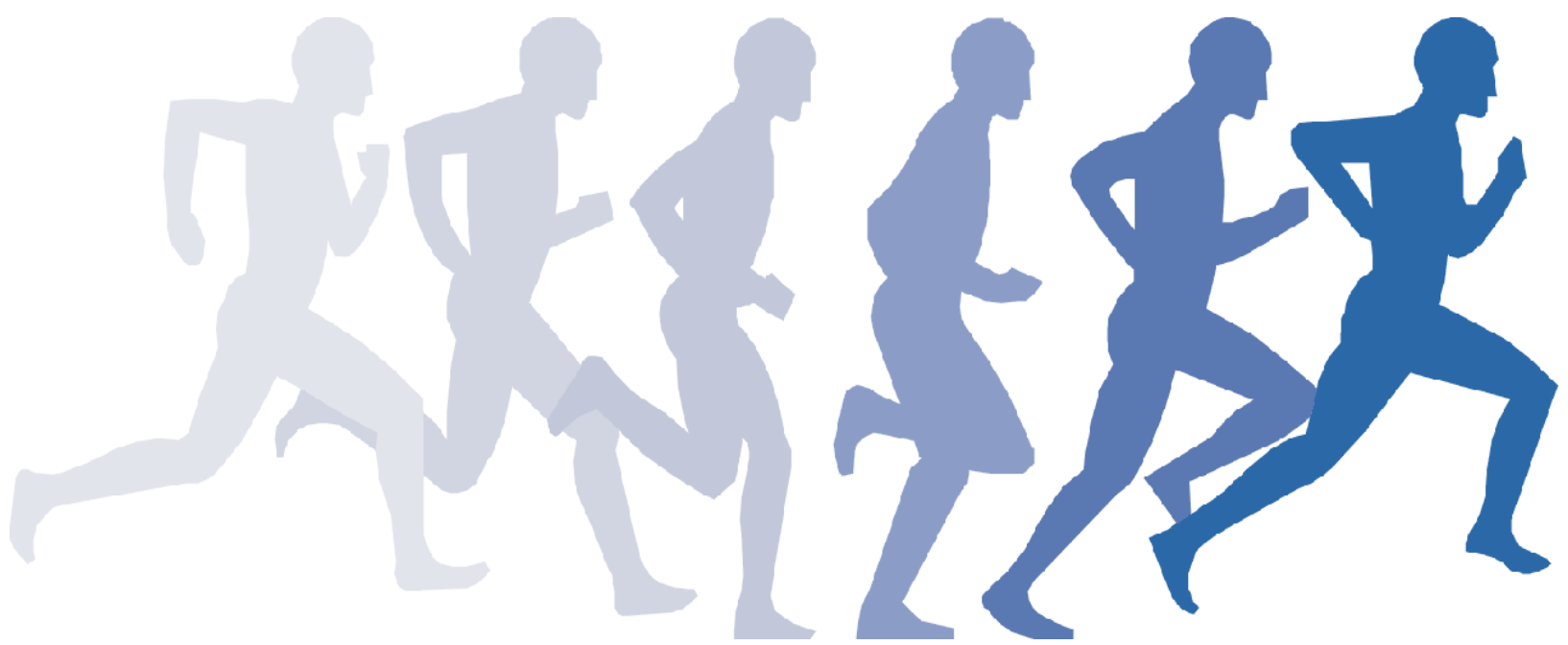